\title{
Periodontal disease in relation to selected parameters of the cardiovascular system in a group of patients with stable angina pectoris
}

\author{
MONIKA WŁOSOWICZI , BEATA WOŻAKOWSKA-KAPŁON ${ }^{1,2}$, RENATA GÓRSKA \\ ${ }^{1}$ Faculty of Health Sciences, The Jan Kochanowski University, Kielce, Poland \\ ${ }^{2} 1$ st Clinical Department of Cardiology, Swietokrzyskie Cardiology Center, Kielce, Poland \\ ${ }^{3}$ Department of Periodontology, Institute of Dentistry, Medical University of Warsaw, Poland
}

\begin{abstract}
Introduction: Periodontal diseases (PD), which are the cause of chronic inflammatory processes, can develop increased susceptibility to vascular diseases through atherosclerosis. Due to the raised inflammatory and thrombotic risk, $P D$ can have a significant influence on the course and results of stable angina pectoris (SAP).

Objectives. The aim of the study is to evaluate the influence of chosen PD parameters on selected cardiovascular system parameters, and the correlation between chosen parameters of periodontitis and cardiovascular system parameters.

Material and methods: the case group included 67 patients with SAP, $\leq 60$ years of age. The occurrence of well-known cardiovascular disease risk factors was evaluated on the basis of the clinical interview, clinical examination and laboratory tests. The occurrence of known risk factors for cardiovascular diseases $(C V D)$ was established on the basis of the interview, clinical research and laboratory tests. Periodontal examination included API (approximal plaque index), CAL (clinical attachment level), PD (pocket depth), and BI (bleeding index). IMT (intima-media thickness) and the size of atherosclerotic plaque in carotid arteries were assessed by ultrasound examination. Segmental contractility abnormalities were assessed on the basis of echocardiography examination, presence of the single-vessel vascular and multi-vessel vascular disease on the basis of angiographic examination.

Results: In the study group of patients, numerous risk factors and a higher level of API, CAL, PD and BI were observed. A higher prevalence of multi-vessel disease (75\%) than single-vessel disease $(25 \%)$ was noted on the basis of angiographic examination. Patients with contractility abnormalities demonstrated also poor oral cavity health. In addition, a higher concentration of CRP $(3.2 \mathrm{mg} / \mathrm{dl})$, fibrinogen $(3.3 \mathrm{~g} / \mathrm{l})$ ) and the progression of atherosclerosis, e.g. increased IMT $(2.1 \mathrm{~mm})$ and formation of atherosclerotic plaques were noted. Results of multivariate logistic regression demonstrated that API and $P D$ had a significant influence on IMT. In patients with $B M I \geq 30 \mathrm{~kg} / \mathrm{m}^{2}$, the risk of increased IMT $(O R=4.67)$ was fourfold higher.
\end{abstract}

Summary: Periodontitis may influence the occurrence and course of the atherosclerotic process in persons with stable angina.

Key words: periodontal diseases, atherosclerosis, cardiovascular diseases.

(Centr Eur J Immunol 2014; 39 (2): 181-186)

Cardiovascular diseases, including coronary disease, are at present the main cause of death in middle-aged and old-aged adults [1]. The most frequent form of the disease is stable angina pectoris (SAP). The frequency of occurrence of the disease increases with age for both sexes [2]. Initiation of atherosclerotic plaques is preceded by the dysfunction of endothelium caused by its local damage [3]. The classical factors causing damage of endothelium are oxidized low-density lipoproteins (oxy-LDL), tobacco smoking, arterial hypertension and diabetes. Apart from the factors mentioned above, there is scientific evidence supporting the assertion that inflammatory processes also facilitate development of atherosclerotic plaques. An indicator of chronic inflammation, typical of atherogenesis, is an increase in concentration of C-reactive protein (CRP), which in stable angina is an independent predictor of heart failure incidents for both men and women [4]. During twoyear observation of 2121 patients with SAP it was found

Correspondence: Beata Wożakowska-Kapłon MD, PhD, I Oddział Kardiologii, Świętokrzyskie Centrum Kardiologii, Grunwaldzka 45, 25-736, Kielce, tel. +48 3236713 01, e-mail: bw.kaplon@ poczta.onet.pl 
that in patients with $\mathrm{CRP}>3.6 \mathrm{mg} / \mathrm{dl}$, the risk of cardiac arrest or sudden cardiac death was doubled in comparison to patients with a normal CRP level.

The mediators of atherosclerotic plaque development are cytokines such as tumor necrosis factor $\alpha$ (TNF- $\alpha$ ), interleukins, interferon- $\gamma$ (IFN- $\gamma$ ); growth factors including insulin-like growth factor 1 (IGF-1), platelet-derived growth factor (PDGF), transforming growth factor $\beta$ (TGF- $\beta$ ) and vascular endothelial growth factor (VEGF) [5].

Within the last decade, it has been frequently pointed out that periodontal diseases (PD) constitute an independent risk factor for cardiovascular diseases. It has been demonstrated that common risk factors and similar elements of the inflammatory process lie at the basis of periodontal diseases and atherosclerosis, both in patients with SAP and acute coronary syndromes (ACS).

Periodontal diseases, similarly to atherosclerosis, have chronic, long-term, asymptomatic course, which results in irreversible changes in periodontium. Numerous epidemiological research projects showed that a poor condition of the oral cavity, chronic periodontitis or numerous missing teeth correlate with atherosclerosis in arterial vessels and advanced coronary disease [6,7]. It is noted that in

Table 1. Baseline clinical characteristics (mean \pm STD) of the group with SAP (mean age $53 \pm 4$ )

\begin{tabular}{|c|c|}
\hline Men & $43(64 \%)$ \\
\hline Women & $24(36 \%)$ \\
\hline Tobacco smoking & $28(42 \%)$ \\
\hline History of arterial hypertension & $35(52.2 \%)$ \\
\hline History of diabetes & $15(22 \%)$ \\
\hline Hyperlipidemia (mg/dl) & $184 \pm 128.7$ \\
\hline $\operatorname{BMI}\left(\mathrm{kg} / \mathrm{m}^{2}\right)$ & $26.4 \pm 3.8$ \\
\hline $\mathrm{BNP}(\mathrm{pg} / \mathrm{l})$ & $49.0 \pm 30.9$ \\
\hline IMT(mm) & $1.1 \pm 0.4$ \\
\hline $\mathrm{sBP}(\mathrm{mm} \mathrm{Hg})$ & $125.6 \pm 9.9$ \\
\hline API $(\%)$ & $17.0 \pm 13.0$ \\
\hline CAL (mm) & $1.0 \pm 1.2$ \\
\hline $\mathrm{PD}(\mathrm{mm})$ & $1.6 \pm 0.5$ \\
\hline Edentulousness (pts) & $7(10 \%)$ \\
\hline $\mathrm{BI}(\%)$ & $0.8 \pm 2.8)$ \\
\hline $\mathrm{CRP}(\mathrm{mg} / \mathrm{dl})$ & $3.2 \pm 2.3)$ \\
\hline Fibrinogen (g/l) & $3.3 \pm 0.64)$ \\
\hline
\end{tabular}

$\overline{B M I-\text { body mass index, BNP - brain natriuretic peptide, IMT - intima-media }}$ thickness, $s B P$ - systolic blood pressure, API - approximal plaque index, $C A L$ - clinical attachment level, PD - pocket depth, BI-bleeding index, CRP - C-reactive protein the course of periodontal diseases, a high concentration of mediators and pro-inflammatory cytokines is observed, such as TNF- $\alpha$, prostaglandin E2 (PGE-2), interleukin $1 \beta$ (IL-1 $\beta)$, IL-6, proteolytic enzymes, metalloproteinase (MMP), whose presence may not only have a destructive effect on periodontium, but also can induce destabilization of atherosclerotic plaques. Cytokines stimulate liver to produce acute-phase proteins, including C-reactive protein (CRP) and fibrinogen, that is markers of the systemic inflammatory response and thrombotic risk. What is more, the markers can stimulate stratification of ACS risks [8].

The aim of the study is to evaluate the influence of chosen PD parameters on the selected cardiovascular system parameters, and a correlation between chosen parameters of periodontitis and cardiovascular system parameters.

\section{Material and methods}

Sixty-seven hospitalized patients, aged $\leq 60$, with SAP were included in the research. The occurrence of cardiovascular diseases risk factors was evaluated on the basis of the clinical interview, clinical examination and laboratory tests. Elements such as male sex, tobacco smoking, obesity $\left(\mathrm{BMI}>30 \mathrm{~kg} / \mathrm{m}_{\mathrm{c}}\right)$, arterial hypertension and diabetes, CRP concentration $>5 \mathrm{mg} / \mathrm{l}$ and fibrinogen concentration $>4 \mathrm{~g} / \mathrm{l}$ were regarded as risk factors.

Periodontal examination included approximal plaque index (API), clinical attachment loss (CAL), probing depth (PD), bleeding index (BI) and the number of remaining teeth. Intima-media thickness (IMT) and the amount of atherosclerotic plaques in carotid arteries were evaluated on the basis of an ultrasound scan. 16 patients were recommended to undergo coronary angiography, which was performed in order to assess the degree of atherosclerotic changes in coronary vessels. Segmental disorder of myocardial contractility disturbances was evaluated on the basis of echocardiography.

The research project was approved by the Commission of Bioethics of the Swietokrzyskie Region Chamber of Physicians and Dentists (approval number 4/2008).

The present study is a part of a wider project, in which relations between the state of periodontium and advancement of inflammatory processes were examined in patients with stable angina and patients with myocardial infarction.

In statistical analysis for individual quantitative parameters, average values and standard deviation were determined. Spearman's rank correlation coefficient, simple regression analysis with hazard ratio were used. The level of statistical significance was established at $p<0.05$.

\section{Results}

Male patients prevailed in the study group, and the dominant risk factor was tobacco smoking. In a considerable number of cases (Table 1), arterial hypertension, 
Table 2. Comparison of oral health status parameters and chosen cardiovascular parameters

\begin{tabular}{|c|c|c|c|c|c|c|c|}
\hline & BMI & BNP & IMT & sBP & Hyperlipidemia & CRP & Fibrinogen \\
\hline \multicolumn{8}{|l|}{ API } \\
\hline$r$ & 0.511 & 0.245 & 0.368 & 0.581 & -0.024 & 0.127 & 0.261 \\
\hline$p$ & $<0.000$ & NS & $<0.05$ & $<0.0001$ & NS & $<0.05$ & $<0.01$ \\
\hline \multicolumn{8}{|c|}{ CAL } \\
\hline$r$ & 0.512 & 0.484 & 0.256 & 0.527 & 0.039 & 0.283 & 0.261 \\
\hline$p$ & $<0.0001$ & 0.0068 & NS & $<0.0001$ & NS & $<0.01$ & $<0.01$ \\
\hline \multicolumn{8}{|l|}{ PD } \\
\hline$r$ & 0.574 & 0.629 & 0.234 & 0.517 & -0.041 & 0.210 & 0.204 \\
\hline$p$ & $<0.0001$ & 0.0002 & NS & $<0.0001$ & NS & $<0.05$ & $<0.05$ \\
\hline \multicolumn{8}{|l|}{ BI } \\
\hline$r$ & 0.562 & 0.255 & 0.457 & 0.567 & -0.092 & 0.181 & 0.105 \\
\hline $\mathrm{p}$ & $<0.0001$ & NS & 0.0146 & $<0.0001$ & 0.5900 & NS & NS \\
\hline
\end{tabular}

Table 3. Results of imaging examinations (ultrasound, angiography, echocardiography examination) in patients with SAP

\begin{tabular}{ccccc}
\hline IMT $(\mathbf{m m})$ & $\begin{array}{c}\text { Quantity of atherosclerotic } \\
\text { plaque in carotid arteries }(\boldsymbol{n})\end{array}$ & $\begin{array}{c}\text { One-vascular } \\
\text { disease }(\boldsymbol{n})\end{array}$ & $\begin{array}{c}\text { Multi vascular disease } \\
(\boldsymbol{n})\end{array}$ & $\begin{array}{c}\text { Segmental contractility } \\
\text { abnormalities }(\boldsymbol{n})\end{array}$ \\
\hline $2.1 \pm 0,8$ & $17(11 \%)$ & $4 / 16(25 \%)$ & $12 / 16(75 \%)$ & $16 / 29(55 \%)$ \\
\hline
\end{tabular}

IMT-intima-media thickness; STD - standard deviation

diabetes and obesity appeared. The risk factors mentioned above are common for both heart diseases and periodontal diseases. Hypercholesterolemia and increased BNP index were not observed. During periodontal examination, higher levels of API, CAL, PD and BI were observed, which indicates poor dental hygiene and chronic periodontitis. In addition, higher concentrations of CRP and fibrinogen were noted (Table 1). A correlation between oral cavity status indexes (API, CAL, PD, BI) and BMI and oral cavity status indexes and BP indexes was observed. BNP correlated with PD but IMT correlated only with API. The correlations between parameters of periodontitis and inflammatory markers are weak. The strongest correlation occurred between the CRP concentration and clinical attachment loss (CAL) and between fibrinogen concentration and approximal plaque index (API) (Table 2). Among patients with SAP, increased IMT and atherosclerotic plaques in carotid arteries were found (Table 3). A higher prevalence of multi-vessel disease $(75 \%)$ than single-vessel disease $(25 \%)$ was noted on the basis of angiographic examination. Myocardial contractility disturbances appeared in 55\% of the examined patients (Table 3 ). Patients with myocardial contractility disturbances had increased API, CAL, PD, BI and edentulousness was more frequently noted in comparison to patients without myocardial contractility disturbances, however those differences were not significant (Table 4). A correlation between IMT and inflammatory markers (CRP, fibrinogen) and between IMT and oral status parameters (API, BI) was established (Table 5).
Results of multiple logistic regression demonstrated that API and PD had a significant influence on increasing IMT, which is recognized as the indicator of subclinical atherosclerosis. It was also proven that the risk of higher IMT increases with the patients' age and with coexisting tobacco smoking. Obese patients (BMI $\geq 30)$ had a fourfold higher risk of increasing IMT (OR = 4.67) in comparison with normal body mass index patients; in patients with a hypertension risk, IMT increase was twofold in comparison with patients with a normal range of blood pressure $(\mathrm{OR}=2.06)$. The risk of increasing IMT appeared also in patients with hyperlipidemia $(\mathrm{OR}=1.75)$ (Table 6).

Table 4. Comparison means of oral health status parameters in the group of patients with (16 pts) and without (13 pts) segmental contractibility abnormalities

\begin{tabular}{lccc}
\hline Parameter & $\begin{array}{c}\text { Segmental } \\
\text { contractility } \\
\text { abnormalities } \\
(\boldsymbol{n}=\mathbf{1 6})\end{array}$ & $\begin{array}{c}\text { No segmental } \\
\text { contractility } \\
\text { abnormalities } \\
(\boldsymbol{n}=\mathbf{1 3})\end{array}$ & $\boldsymbol{p}$ \\
\hline API $(\%)$ & $42.0 \pm 20.4$ & $34.4 \pm 14.1$ & 0.3440 \\
\hline CAL $(\mathrm{mm})$ & $2.6 \pm 2.2$ & $2.0 \pm 2.0$ & 0.6352 \\
\hline PD $(\mathrm{mm})$ & $2.9 \pm 0.9$ & $2.4 \pm 0.9$ & 0.2463 \\
\hline BI $(\%)$ & $31.5 \pm 17.8$ & $23.5 \pm 16.9$ & 0.1852 \\
\hline Edentulousness $n(\%)$ & $17(58.6 \%)$ & $12(41.4 \%)$ & 0.6670 \\
\hline $\begin{array}{l}\text { API- approximal plaque index; } \text { CAL-clinical attachment level; } P D-\text { pocket } \\
\text { depth; BI- bleeding index }\end{array}$ & & &
\end{tabular}


Table 5. Associations between inflammatory markers (CRP, fibrinogen), oral status parameters (API, CAL, PD, BI) and IMT

\begin{tabular}{cccccccc}
\hline & & CRP & Fibrinogen & API & CAL & PD & BI \\
\hline \multirow{2}{*}{ IMT } & $r$ & 0.416 & 0.442 & 0.368 & 0.256 & 0.234 & 0.457 \\
\cline { 2 - 7 } & $p$ & 0.0480 & 0.0113 & 0.0539 & 0.1887 & 0.2303 & 0.0146 \\
\hline
\end{tabular}

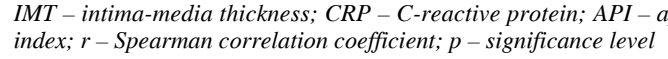

Table 6. Influence of oral health status parameters and independent variables on intima-media thickness (IMT) - multiple logistic regression analysis results. Odds ratio (OR) over one indicates an increased probability of IMT $\geq 0.9 \mathrm{~mm}$

\begin{tabular}{|c|c|c|}
\hline Independent variables & OR $(95 \% \mathrm{CI})$ & $p$ \\
\hline API $(\%)$ & $1.0277(1.0084-1.0473)$ & 0.0048 \\
\hline CAL (mm) & $0.1905(0.0329-1.1038)$ & 0.0643 \\
\hline $\mathrm{PD}(\mathrm{mm})$ & $1.1448(0.0284-0.7377)$ & 0.0200 \\
\hline $\mathrm{BI}(\%)$ & $0.9948(0.9750-1.0149)$ & 0.6080 \\
\hline age & $1.0779(1.0089-1.1515)$ & 0.0262 \\
\hline smoking & $2.3700(0.8946-6.2789)$ & 0.0826 \\
\hline diabetes & $0.4637(0.0038-56.6082)$ & 0.7539 \\
\hline obesity & $4.6745(1.3755-15.8867)$ & 0.0135 \\
\hline arterial hypertension & $2.0625(0.7940-5.3574)$ & 0.0023 \\
\hline hyperlipidemia & $1.7566(0.0852-36.2061)$ & 0.7152 \\
\hline
\end{tabular}

\section{Discussion}

In the discussed group of patients, such classical cardiovascular disease risk factors were observed to a considerable degree as male sex, tobacco smoking, obesity, arterial hypertension, hyperlipidemia and diabetes. The factors are common for both periodontal diseases and heart diseases $[9,10]$.

Numerous research projects showed that patients who possess at least 3 out of 5 features of the metabolic syndrome (abdominal obesity, high concentration of triglycerides, lowered concentration of fraction HDL-cholesterol, elevated arterial pressure, increased fasting glucose concentration), are at a greater risk of cardiovascular complications. Elevated CRP concentration correlates with the occurrence of coronary incidents [11]. In the study group, poor dental hygiene (API) and presence of periodontitis were demonstrated. The research conducted by other authors showed that the presence of dental plaque (biofilm), which is known as the basic risk factor for periodontal diseases, can also occur in cardiovascular diseases [12]. Also Fujita et al. [13] showed that in patients with poor dental hygiene, diseases such as diabetes, arterial hypertension, a high concentration of triglycerides and a low concentration of HDL-cholesterol appear more often. Frequently, in patients with SAP, periodontal disease (which can lead to chronic inflammation) could influence occurrence and course of vascular disease. Moreover, other authors showed that in patients with periodontal disease and presence of dental plaque, myocardial infarction appeared more often than stable angina [14]. In the discussed group of patients, mild periodontitis dominated. This fact can be indicated by higher values of CAL, PD, BI, and moderately increased CRP and fibrinogen concentrations. In the present study, the strongest correlation appeared between CAL, which is an indicator of periodontitis advancement, and CRP concentration and also between API, which indicates the level of dental hygiene, and concentration of fibrinogen. A correlation between API and fibrinogen concentrations confirms participation of dental plaque in occurrence of periodontitis [15]. Moreover, a correlation between cardiovascular parameters such as BNP, BMI, IMT, hypertension and API, CAL, PD was demonstrated. The results may suggest multiple correlations between oral cavity health and cardiovascular diseases. The hypothesis seems to be confirmed by the results of recent research, which suggests a correlation between obesity and periodontitis. In Fukuoka promotion program, in a group of 643 persons aged 1979 , the risk of periodontitis was increased over fourfold in a group of persons with the highest WHR index - BMI $\geq 30 \mathrm{~kg} / \mathrm{m}_{\text {c [16]. }}$.

Edentulousness appeared in $10 \%$ of the examined patients. It is believed that the number of teeth reflects, to a considerable degree, occurrence and course of periodontitis. Holmlund et al. [17] demonstrated that the risk of death caused by MI among patients with less than 10 teeth is 7-fold higher. Numerous studies proved that the more advanced periodontitis the more intense inflammatory and atherosclerotic processes become [18]. A correlation between CRP concentration and development in atherosclerosis in coronary vessels was statistically confirmed [19, 20]. A raised concentration of fibrinogen associated with an increased aggregation of erythrocytes, increased viscosity and microcirculatory resistance in patients with arterial hypertension, stable and unstable angina and myocardial infarction were observed [21]. According to the present study, an increased CRP concentration relates to coexistence of periodontal disease and coronary disease. Numerous studies showed that proper periodontal therapy can significantly improve the condition of periodontium and reduce inflamma- 
tory activity of the organism through, among other things, reduction of the concentration of CRP and fibrinogen [22]. The progression of the atherosclerotic process in arterial vessels in the discussed group of patients was reflected by increased IMT, atherosclerotic plaque, multi-vessel lesions in coronary vessels and presence of myocardial contractility disturbances. Buhlin et al. [23] showed that the extent of periodontitis correlates with atherosclerotic lesions in coronary vessels determined on the basis of angiographic examination in patients with cardiovascular diseases.

The same authors also demonstrated that the patients with diagnosis based on echocardiogram with lesions in segmental myocardial contractility disorder had poorer API and poorer condition of periodontium in comparison with patients without such lesions (absence of essential differences between the two groups may stem from the fact that the SAP group was quite uniform in terms of general health and condition of periodontium). What is more, that correlation between IMT, API and BI can suggest that poor oral cavity and periodontium condition may increase IMT, which is an indicator of subclinical atherosclerosis.

What is more, the results of multivariate logistic regression demonstrated that increased IMT (indicator of subclinical atherosclerosis) was significantly influenced by dental hygiene assessed with API and degree of progression of periodontitis assessed with PD. Schilinger et al. obtained similar results [6] demonstrating the relation between atherosclerotic changes in arterial vessels and DMFT (decayed, missing, filled teeth), plaque index and the number of teeth. In his research conducted on a group of 6017 persons, Beck et al. [24] showed a statistically significant relation between destruction of periodontium and thickness of atherosclerotic changes in the arterial wall. In addition, it was also proven that IMT was higher in older patients who smoke tobacco. In obese patients, the risk of increasing IMT was fourfold higher $(\mathrm{OR}=4.67)$ and in patients with hypertension the risk was twofold higher $(\mathrm{OR}=2.06)$. The results of the research may suggest that poor periodontium health and other risk factors (representative for both periodontitis and cardiovascular diseases) can result in appearance and exacerbation of cardiovascular incidents.

\section{Summary}

Periodontitis with numerous risk factors can initiate and influence the course of the atherosclerotic process in patients with stable angina pectoris.

The authors declare no conflict of interest.

\section{References}

1. Yach D, Hawkes C, Gould CL, et al. (2004): The global burden of chronic diseases: overcoming impediments to prevention and control. JAMA 291: 2616-2622.
2. Fox K, Garcia MA, Ardissino D, et al. (2006): Task Force on the Management of Stable Angina Pectoris of the European Society of Cardiology; ESC Committee for Practice Guidelines (CPG). Guidelines on the management of stable angina pectoris: executive summary: the Task Force on the Management of Stable Angina Pectoris of the European Society of Cardiology. Eur Heart J 27: 1341-1381.

3. Lietava J, Vohnout B, Penz P, et al. (2012): Relationship of self-reported exercise tolerance with inflammatory markers in women with stable ischemic heart disease. Neuro Endocrinol Lett 2012; 33 Suppl 2: 50-54.

4. Haverkate F, Thompson SG, Pyke SD, et al. (1997): Production of C-reactive protein and risk of coronary events in stable and unstable angina. European Concerted Action on Thrombosis and Disabilities Angina Pectoris Study Group. Lancet 349: 462-426.

5. Puddu GM, Cravero E, Arnone G, et al. (2005): Molecularaspects of atherogenesis: newinsights and unsolvedquestions. J Biomed Sci 12: 839-853.

6. Schillinger T, Kluger W, Exner M, et al. (2006): Dental and periodontal status and risk for atherosclerosis: the inflammation and carotid artery study dental substudy. Stroke 37: 2271-2276.

7. Desvarieux M, Demmer RT, Rundek T, et al. (2003): Relationship between periodontal disease, tooth loos and coronary artery plaque: the Oral and Vascular Disease Epidemiology Study (INVEST). Stroke 34: 2120-2125.

8. Hingorani AD, D'Aiuto F. (2008): Chronic inflammation, periodontitis and cardiovascular disease. Oral Disease 14: 102-104.

9. Losche W (2007): Periodontitis and cardiovascular disease: periodontal treatment lowers plasma cholesterol. Editorial. South Med J 100: 663-664.

10. Fardi A, Papadimitriou D (2007): Periodontal and atherosclerosis-induce diseases. Systematic reviews. Int Angiol 26: 197-205.

11. Yin WH, Chen JW, Jen HL, et al. (2004): Independent prognostic value of elevated high-sensivity C-reactive protein in chronic heart failure. Am Heart J 147: 931-938.

12. Tezal M, Scannpieco FA. Wactawski-Wende J, Grossi SG (2006): Supragingival plaque may modify the effect of gingival bacteria on attachment loss. J Perodontol 5: 808-813.

13. Fujita M, Koichi U, Hata A (2009): Lower Frequency of daily teeth brushing is related to high prevalescence risk factor. Exp Biol Med 234: 387-394.

14. Janket SJ, Baird AE, Chuang SK, et al. (2003): Meta-analysis of periodontal disease and risk of coronary heart disease and stroke. Oral Surg Oral Med Oral Pathol Oral Radiol Endod 95: 559-569.

15. Ridker M, Silvertown JD (2008): Inflammation, C-reactive protein, and atherothrombosis. J Periodontol 79: 1544-1551.

16. Saito T, Shimazaki Y, Koga T, et al. (2001): Relationship between upper body obesity and periodontitis. J Dent Res 80: 1631-1636.

17. Holmlund A, Holm G, Lind L (2010): Number of teeth as a predictor of cardiovascular mortality in a cohort of 7,674 subjects followed for 12 years. J Periodontol 81: 870-876.

18. Kodovazenitis G, Pisavos CH, Papadimitriou L, et al. (2011): Periodontal disease is associated with higher levels of C-reactive protein in non-diabetic, non-smoking acute myocardial infarction patients. J Dent 39: 849-854. 
19. Hosseinsabet A, Mohebbi A, Almasi A (2008): C-reactive protein and coronary calcium score association in coronary artery disease. Cardiol J 15: 431-436.

20. Lorenz MW, Karbstein P, Markus HS, et al. (2007): High-sensitivity C-reactive protein is not associated with carotid intima-media progression: the carotid atherosclerosis progression study. Stroke 6: 1774-1779.

21. Amabile N, Susini G, Pettenati-Soubayroux I, et al. (2008): Severity of periodontal disease correlates to inflammatory systemic status and independently predicts the presence and angiographic extent of stable coronary artery disease. J Intern Med 263: 644-652.

22. Duan XQ, Ouyang XY, Hu R (2009): Effect of initial periodontal therapy on chronic periodontitis patients with stable coronary heart disease. Zhonghua Kou Qiang Yi Xue Za Zhi 44: 351-354.

23. Buhlin K, Mäntylä P, Paju S, et al. (2011): Periodontitis is associated with angiography verified coronary artery disease. J Clin Periodontol 38: 1007-1014.

24. Beck DJ, Offenbacher S, Williams R (1998): Periodontitis. A risk factor coronary heart disease? Ann Periodontol 3: 127-141. 